\title{
An Instrument for Assessing Knowledge Gain in a First Course in Circuit Theory
}

\author{
Vishnu K. Lakdawala, Stephen A. Zahorian, Oscar R. González, \\ Amit Kumar H., and James F. Leathrum, Jr. \\ Department of Electrical and Computer Engineering \\ Old Dominion University \\ Norfolk, VA 23529
}

\begin{abstract}
Although there has been considerable research on the development and use of assessment instruments to measure the effectiveness of various pedagogical approaches to teaching introductory physics classes (Hestenes et al. ${ }^{1}$, Hestenes et $\mathrm{al}^{2}$, Hake ${ }^{3}$, Saul et al. ${ }^{4}$ ) and other science courses (for example, see Vosniadou ${ }^{5}$ ), there is relatively little similar work that has been done to develop assessment instruments for the first circuit theory course that is taught in electrical and computer engineering. Given the large numbers of students nationwide who take such a course, the challenge this course presents to beginning engineering students, and the introduction of new approaches to teach this material, an instrument similar to those available for physics is needed to identify student misconceptions at the beginning of the class and to measure the normalized learning gain at the end of the class $\left(\mathrm{Hake}^{3}\right)$. These gains and other metrics can then be used to compare the effect of different teaching methods. In addition, this same instrument or portions of it can be offered at later times in the curriculum to measure retention and reinforcement from other courses. This concept-based testing approach is useful to examine the overall effectiveness of the circuit component of a curriculum and could thus be used as part of the continuous self-improvement process required under the ABET 2000 rules.
\end{abstract}

\section{Introduction}

In recent years, in response to the pressures from both industry and academic accreditation bodies, higher education institutions are incorporating more and more student learning outcomes and assessment techniques in their educational programs and courses. Student learning outcomes and assessment are major criteria included in the Accreditation Board of Engineering and Technology (ABET) 2000 criteria. This is further substantiated by the many recent education related conferences which include assessment as a key subject area. Recently the IEEE Transactions on Education devoted a complete special issue on assessment (McGourty and Kerns $^{6}$ ). The issue contains papers on development, implementation, and institutionalization of educational assessment in engineering education. A number of assessment instruments that assess multiple dimensions of learning are also available (for example, see $\mathrm{FLAG}^{7}$ ) to faculty in science, mathematics, and engineering. In addition, over the past several years, considerable effort has been devoted to research in the area of technology-enhanced education. Progress has been made, addressing a variety of educational needs, ranging from supplements to existing 
courses, to complete on-line courses, to complete on-line programs. Despite all this effort, hype, and even product development, most of the courseware material available for use at the college level is still not considered as effective as a professor lecturing and leading discussions with students. Most of the work is driven more by convenience factors in continuing education due to the increasingly mobile student population ("anytime, anyplace," education), perceived economies of scale, and to a certain extent just because the technology is available. Nevertheless, faculties working on a daily basis with students continue to experiment with new teaching techniques to improve the educational process, allowing students to learn more in less time, to understand more deeply, and to enjoy their learning experience more. Assessment is critical to determine the effectiveness of these new techniques in many different settings.

The present state of affairs in education, and the current trend towards assessing student, faculty, and even complete educational programs, leads us to the conclusion that focused, long-term research is needed to move forward. In order to address some of these issues, a research group comprising of the authors of this paper has been formed working for Technology Enhanced Education (http://www.tee.odu.edu/). The particular focus of our research is to develop and implement a method to dynamically schedule and integrate currently available assessment instruments that assess multiple dimensions of learning. Our group will attempt to use these instruments to improve student learning, instruction methods, course content, and the program of study.

The work reported in this paper represents the initial phases of our work. In particular, this paper describes the development of the alpha version of a test instrument that is intended to assess the student's understanding of fundamental concepts of circuit theory, such as component relations and connection laws. The multiple-choice questions are "concept-based," -- that is most questions have very few numerical quantities, and most questions do not require equation solving to determine the answers.

This single test is intended to be administered at multiple times in the curriculum, and particularly at the beginning and end of the first circuits' course. A comparison of the normalized learning gain in each running of the course is thus expected to be one measure of the effectiveness of the teaching methods used each time the course is taught. Such a test could also be administered at other times in the overall curriculum to measure retention of concept information over time as well as the degree of concept reinforcement from other courses.

\section{Background}

Concept diagnostic tests are employed to study conceptual gains, identify weaknesses in understanding, and to expose a priori misconceptions $\left(\mathrm{Zelik}^{8}\right)$. Extensive field-testing coupled with careful development work can be used to insure valid tests. The tests are generally short multiple-choice format instruments, thus reducing intrusion into class time and making them easy to score. Developing a reliable and valid concept test is a major, long-term undertaking and consequently only a limited number of such tests (mostly in Physics and Astronomy) are currently available. There is relatively little similar work that has been done to develop assessment instruments for the first circuit theory course in electrical and computer engineering. Finelli and Wicks (Finelli and Wicks ${ }^{9}$ ) presented the results of one such instrument for a circuits' 
course. They developed two tests. One test was offered at the beginning of the first course and the other test at the end and at later times in the curriculum. Neither test was designed to be offered as a pre/post test and cannot be used to measure the learning gain or the effect of the teaching method. Recently, faculty associated with the National Science Foundation sponsored Foundation Coalition have started to develop concept inventories for several engineering topics. Two such inventories are currently being designed for time and frequency domain DC and AC circuit analysis.

In Physics, there currently are at least two conceptual diagnostic instruments for electrical circuits. The Electric Circuit Conceptual Examination (ECCE) was developed by Prof. David R. Sokoloff at the University of Oregon and is available, for example, as one of the assessment resources from the Physics Workshop at Dickinson College (Conceptual Learning Assessments ${ }^{10}$ ). A second test is called Determining Interpreting Resistive Electric Circuits Concepts Test (DIRECT), and is limited to resistive circuits. The analysis of the DIRECT test

results appears in the dissertation by Engelhardt (Engelhardt ${ }^{11}$ ). The physics education community has also published research results on student misconceptions on electrical circuits. An extensive listing of references is included in Meltzer ${ }^{12}$. In the Oersted Award lecture in 2001, McDermott ${ }^{13}$ reported that research using conceptual electrical circuits questions did not reveal any improvement from attending lectures. This lack of conceptual learning was a motivation for the Physics by Inquiry teaching technique.

The first version of our electrical circuit concept diagnostic test was done independently from these other tests. Following the analysis of the current test results, we will consider working with the authors of other similar circuit diagnostic tests to adopt some of their test items or modified versions of them. The modification may be necessary since the ECCE and DIRECT tests were developed for students taking physics. The revised test will then be validated for use in an electric engineering circuit theory course. The results of this test will be reported in a future publication.

\section{Concept Test}

The current version of the concept diagnostics test consists of fifteen multiple-choice questions based on fundamental topics typically covered in a first course in circuit theory taught in electrical and computer engineering. The topics included are connection laws - namely Kirchoff's current and voltage laws, Ohm's law for resistors, series and parallel connections, passive sign convention, circuit elements such as resistances and capacitors and simple switching circuits. The following table shows the distribution of the questions for the various topics. Note that some questions pertain to more than one topic area.

Most questions do not have numerical values and do not require equation solving to determine the answer. A typical question is of the form, if a certain resistor in a circuit is increased in value, does the current in branch 1, increase, decrease, or stay the same. About 60 percent of the questions are based on ideas and concepts the students should have learned and mastered in their high school physics or undergraduate physics classes prior to taking the test and the reminder are based on material they are expected to learn in the Circuits 1 course. 


\section{Table 1:Distribution of the questions for the various topic areas}

\begin{tabular}{|c|c|}
\hline Topic Area & $\begin{array}{c}\text { Number of } \\
\text { Questions }\end{array}$ \\
\hline $\begin{array}{c}\text { Ohms Law, Kirchoff's } \\
\text { Voltage and Current Laws }\end{array}$ & 3 \\
\hline Passive Sign convention & 1 \\
\hline Series and Parallel Circuit & 5 \\
\hline $\begin{array}{c}\text { Capacitor and simple } \\
\text { switching circuits }\end{array}$ & 5 \\
\hline Resistance & 8 \\
\hline Dependent Source & 1 \\
\hline
\end{tabular}

To evaluate knowledge gain and retention, the concept diagnostic was administered twice (week 6 and week 14) during the Fall 2001 semester to two cohorts of students--one group taking the Circuit Theory 1 (ECE 201) course, and the second group taking the follow-up Circuit Theory 2 (ECE 202) course. The test was again administered in the beginning of the spring 2002 semester for the same two classes. Thus, some students have taken the test once, some students twice, and some three times. These students are in their sophomore year of the electrical or computer engineering program. Although ideally the tests should be given at the beginning and end of the semester, since the test was still under development, it was not given the first time until about six weeks into the Fall 2001 semester. The students taking these tests have had the necessary prerequisite background in physics and mathematics. In order that meaningful conclusions can be made based on the results of these tests, motivational incentives were given to students so they would take the tests seriously. For the cases reported in this paper, the students were given credit for one homework assignment for taking the test each time irrespective of test performance, plus a small amount of bonus regular exam credit based on diagnostic test performance. In fall of 2001, the Circuit Theory 1 class had 60 students and the Circuit Theory 2 had 36 students. In spring of 2002, the Circuit Theory I class had 36 students, and the Circuit Theory II class had 42 students. It should be noted that in spite of the incentives given, not every student in the class took all the tests. Each test was given during a fifty-minute class period. Even though the students could use the full class time, the majority of the students took about 25 minutes, with only 10 percent of the class taking the full 50 minutes for the test.

\section{Results}

A summary of the results for the two groups of students, Circuit Theory I (ECE 201) students and Circuit Theory II (ECE 202) students, are shown in the following tables. Each test question is equally weighted with a maximum normalized score being 100 . Table 2 summarizes the performance of the ECE 201 students, for each of the three times the test was given in ECE 201. Table 3 summarizes the results for the ECE 202 students, again for each of the three times the test was given in ECE 202. 
Table 2:Test results for Circuit Theory 1 students

\begin{tabular}{|c|c|c|c|}
\hline \multirow[b]{2}{*}{ ECE 201} & \multicolumn{2}{|c|}{ Fall 2001} & \multirow{2}{*}{$\begin{array}{c}\text { Spring } \\
2002 \\
\text { Posttest2 } \\
\text { Week } 1\end{array}$} \\
\hline & $\begin{array}{l}\text { Pretest } \\
\text { Week } 6\end{array}$ & $\begin{array}{c}\text { Posttest } 1 \\
\text { Week } 14\end{array}$ & \\
\hline Number of Students & 60 & 47 & 40 \\
\hline Mean & 45.38 & 47.60 & 50.50 \\
\hline Median & 46.70 & 46.70 & 53.30 \\
\hline Mode & 40.00 & 40.00 & 60.00 \\
\hline STDEV & 15.65 & 16.64 & 15.08 \\
\hline $\mathrm{HIGH}$ & 86.70 & 86.70 & 73.30 \\
\hline LOW & 6.70 & 13.30 & 20.00 \\
\hline
\end{tabular}

Table 3: Test results for Circuit Theory II students:

\begin{tabular}{|c|c|c|c|c|}
\hline \multirow{2}{*}{\multicolumn{2}{|c|}{ ECE 202}} & \multicolumn{2}{|c|}{ Fall 2001} & \multirow{2}{*}{$\begin{array}{c}\text { Spring } \\
2002 \\
\text { Week } 1\end{array}$} \\
\hline & & $\begin{array}{l}\text { Pretest } \\
\text { Week } 6\end{array}$ & $\begin{array}{l}\text { Posttest } \\
\text { Week } 14\end{array}$ & \\
\hline & Number of Students & 36 & 16 & 39 \\
\hline & Mean & 46.86 & 55.41 & 50.61 \\
\hline & Median & 46.70 & 53.30 & 53.3 \\
\hline & Mode & 46.70 & 60.00 & 53.3 \\
\hline & STDEV & 15.65 & 15.75 & 15.16 \\
\hline & HIGH & 73.30 & 86.70 & 73.3 \\
\hline & LOW & 13.30 & 33.30 & 20.0 \\
\hline
\end{tabular}

A few observations about the data are as follows:

- The average test scores range from $45.38 \%$ to $55.41 \%$. Standard deviations within a class range from about $15 \%$ to $17 \%$. The median and the mode are typically very similar and close to the mean.

- The scores do increase from the pretest to the posttest, but only slightly.

- The scores for ECE 202 are somewhat higher than for ECE 201, but again only by a small amount. 


\section{Analysis of the Results}

In order to analyze results in more detail, two cohorts of students were identified. The first group of 26 students took the exam 3 times - twice in the fall of 2001 as ECE 201 students, and once in spring of 2002 as ECE 202 students. The second group of 16 students took the exam twice as ECE 202 students in fall of 2001. For these two cohorts (or "matched" data sets), the results were further analyzed based on Hake's model of normalized learning gain. The average normalized learning gain as defined by $\mathrm{Hake}^{3}$ was computed as follows:

$$
\begin{aligned}
\text { Average Normalized Gain } & =\langle g\rangle=\frac{\text { gain }}{\text { max. possible gain }} \\
& =\frac{\langle\text { post }\rangle-\langle\text { pre }\rangle}{100-\langle\text { pre }\rangle}
\end{aligned}
$$

where the angle brackets " $<\ldots>$ " indicate an average over the students taking the specified test. This metric was computed for the matched data sets of students that took the exam more than once. Another related statistic is, $g_{\text {ave }}$, the average of normalized learning gains for each student in the matched set. This is computed as follows:

$$
g_{\text {ave }}=\frac{1}{N} \sum_{i} g_{i}=\frac{1}{N} \sum_{i} \frac{\text { post }_{i}-\text { pre }_{i}}{100 \%-\text { pre }_{i}}
$$

where $\mathrm{N}$ is the number of students, and $\operatorname{post}_{i}$ and pre $_{i}$ denote the post and pre test scores of the $i^{\text {th }}$ student.

This metric allows the analysis of the distribution of learning gains. Hake points out that as the matched set grows, $g_{\text {ave }}$ will approximate $\langle g\rangle$. Tables 4 and 5 give the results of the learning gain metrics for cohort 1 (first took test as ECE 201 student) and cohort 2 (first took test as ECE 202 student) respectively. Note there are separate columns for each combination of test times (pre-post1, pre-post2, and post1-post2. The last column of Table 4 gives an indication of retention over the holiday break.

Table 4: Cohort 1 Change/Gain Scores

$$
\text { Pre - Post } 1 \quad \text { Pre - Post2 Post1 - Post2 }
$$

$\begin{array}{cccc}\mathrm{N} & 26 & 26 & 26 \\ <\mathrm{g}> & 0.07 & 0.09 & 0.02 \\ \mathrm{~g}_{\mathrm{ave}} & 0.04 & 0.06 & -0.03 \\ \sigma_{\mathrm{gi}} & 0.32 & 0.27 & 0.31\end{array}$




\section{Table 5: Cohort 2 Change/Gain Scores}

Pre - Post1

$\mathbf{N}$

$<\mathrm{g}>$

gave

$\sigma_{\text {gi }}$
16

0.09

0.06

0.28

To give another perspective on the learning gains, histograms for the learning gains are plotted in Figure 1 and Figure 2 for the two cohorts of students summarized in Tables 3 and 4.

Distribution of Gains for Cohort 2

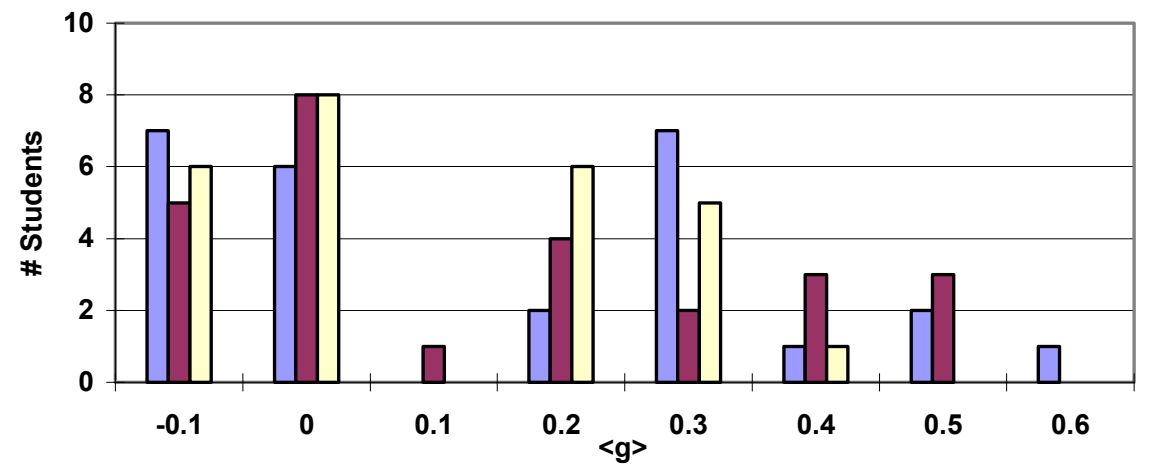

$\square$ Pre-Post1 $\square$ Pre-Post2 口Post1-Post2

Figure1 : Distribution of normalized gains for Cohort 1

Distribution of Gains for Cohort 2

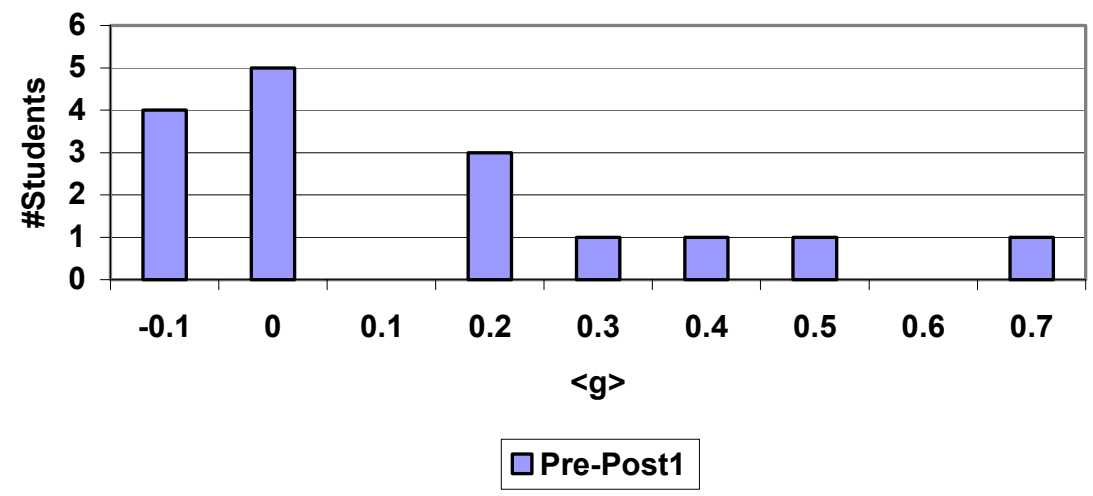


Figure 2: Distribution of normalized gains for Cohort 2

The above results show that:

- The average normalized gain $<\mathrm{g}>$, between the pre- and post- tests I, for the ECE 201 course was 0.07 as compared with 0.09 for the ECE 202 course. These numbers are quite low indicating a little or no gain during the course. According to Hake, "high-g" courses are those with $(<\mathrm{g}>)>0.7$, "medium-g" courses are those with $0.7>(<\mathrm{g}>)>0.3$, and "low-g" courses are those with $(<\mathrm{g}>)<0.3$.

- From the histograms, it can be seen that a significant population of the students had negative or zero gain, thereby bringing the average $<\mathrm{g}>$ value down.

- Another reason for the low values of $<\mathrm{g}>$ could be that the courses were taught using the traditional methods of instruction in the classroom and no "Interactive Engagement" methods were employed during the teaching of these courses.

- The $<\mathrm{g}>$ values increased from 0.07 to 0.09 for the post 1 and post 2 tests for cohort 1 . This indicated a small improvement in the student performance over the Christmas break, when no instruction was provided.

- It also appears that although the questions chosen for the very first alpha version of the diagnostics tests covered the intended topics, a quick overview of the students' performance indicated difficulties in some questions by most of the students, whereas the majority of students answered some questions correctly. It is possible that the more difficult questions should be rewritten.

- The $\mathbf{g}_{\mathrm{ave}}$ values for the two groups of students are 0.04 and 0.06 respectively.

\section{Discussion of Results:}

The key observation from the results given above is that for the current alpha version of the instrument that there was very little improvement in average test performance between students in the first few weeks of a circuits 1 course (42\%) and students on the last day of a circuits II course $(55 \%)$. Results for the other two cases (end of circuits 1 course, beginning of circuits 2 course) are within this small range. The $<\mathrm{g}>$ values for matched data indicate even smaller improvements. Although this is not the result we had anticipated or hoped for, from a research on educational methods perspective, the results are very interesting. In particular, the following possibilities should be considered:

1. Despite our best efforts, it is still possible that the concept test constructed by the team of electrical engineering faculty is not an appropriate test of fundamental concepts for a first course in circuits. However, the committee did carefully evaluate all questions, with the goals of covering the basic concepts in circuit theory, of minimizing redundancy, and attempted to scale questions for medium difficulty level. It is possible that the test was too difficult.

2. The students may not have been sufficiently motivated to excel on these tests. Although the students were given some credit for taking the test, it is likely that some students did not take the test seriously. However, it does not seem likely there would have been a systematic difference between the test given to the beginning group of students, and those students nearing the end of their formal study of circuits. 
3. It is possible that our current coverage of circuit theory, which we believe is a fairly conventional and standard approach, simply does not work well in terms of improving students' grasp of the fundamental circuit concepts. It is this last possibility, although a big source of concern that seems most likely.

4. It is likely that the real interpretation of the results should be some combination of the above three factors. The results must also be considered taking into consideration the relatively small number of data points obtained thus far. The mean values did trend in the right direction, in terms of more advanced students generally scoring somewhat higher.

\section{Conclusions and Future Work}

This paper presents the preliminary results of an alpha version of a concept diagnostics test for assessing student understanding of the fundamental concepts for an introductory course in circuit theory in an electrical and computer engineering program. Preliminary results obtained indicate that our students are not improving by a significant amount in grasping the important fundamental concepts in circuit theory as they progress through the program. This is of obvious concern. Further work is planned to continue to administer the test to additional groups of students, and refine the test questions if necessary. We are also considering other similar tests ${ }^{10}$ that have been developed and will possibly incorporate parts of them. In the long-term, we plan to work together with other colleges (for example community colleges offering similar courses) and also to offer tests for other topics in the ECE program. The circuits test will be administered to the present cohort of students at other time times in the overall curriculum to measure retention of concept information over time as well as the degree of concept reinforcement from other courses. Also, we need to do more analysis of the test questions and the distracters (incorrect answers). The test will evolve into a beta version by fall 2003. With the beta test faculty in other universities will be sought to administer the test and to report the data.

The work reported is a part of our long-term plan for the development and implementation of a methodology to dynamically schedule and integrate currently available assessment instruments that assess multiple dimensions of learning with multiple resolutions. It is believed that this work will eventually lead to the development of test instruments that aid student learning.

\section{Bibliography}

1. Hestenes, David and Wells, and Malcolm (1992). A mechanics baseline test. The Physics Teacher, 30, 159-166.

2. Hestenes, David, Wells, Malcolm, Swackhamer, and Gregg (1992). Force concept inventory. The Physics Teacher, 30 (3): 141-151.

3. Hake, Richard R.. "Interactive-engagement versus traditional methods: A six-thousand-student survey of mechanics test data for introductory physics courses." American Journal of Physics (1998): 64-74.

4. Saul, Jeffrey M., Deardorff, Duane L., Abbott, David S., Allain, Rhett J., and Beichner, Robert J., Evaluating introductory physics classes in light of ABET criteria : An Example of SCALE-UP Project, Proceedings of the 2000 Annual meeting of the American Society for Engineering Education.( also visit for related publications http://www.ncsu.edu/PER/articles.htm) 
5. Vosniadou, S. (1990). Conceptual development in astronomy. In S. Glynn, R. Yeany, and B. Britton (eds.), The psychology of learning science (pp. 149-177). Hillsdale, NJ: Lawrence Erlbaum.

6. McGourty, J. and Kerns, S., (Eds). "Special Issue on Assessment." IEEE Transactions on Education, 46 (2) (2000): 77-243.

7. FLAG, Field-tested Learning Assessment Guide, (January, 2002),

http://www.wcer.wisc.edu/nise/CL1/flag/default.asp

8. Zeilik, M., (January, 2002), "Classroom Assessment Techniques - Conceptual Diagnostic Tests," http://www.wcer.wisc.edu/nise/cl1/flag/cat/diagnostic/diagnostic7.htm

9. Finelli, CJ. and Wicks, M.A., An Instrument for Assessing the effectiveness of the circuits curriculum in an electrical engineering program, IEEE Transactions on Education, 46 (2) (2000): 137-142.

10. Conceptual Learning Assessments, (January 2002), http://physics.dickinson.edu/PhysicsPages/Workshop_Physics/Instructor_Resources/Curricular_Materials/Conc eptual_Assessments.

11. Engelhardt, Paula Vetter, Examining Students' Understanding of Electrical Circuits Through Multiple-Choice Testing and Interviews (Examinations), Ph.D. Dissertation, North Carolina State University (1997).

12. Meltzer, D., (1999), Addressing Learning Difficulties with Circuits: An "Aufbau” Approach, http://www.public.iastate.edu/ pper/talks/aapt-san-an-99.pdf

13. McDermott, L., (2001), Physics Education Research: The key to student learning, Oersted Award Lecture presented at the Winter 2001 Meeting of the American Association of Physics Teachers, http://www.phys.washington.edu/groups/peg/Oersted.pdf.

\section{VISHNU K. LAKDAWALA}

Vishnu Lakdawala is an Associate Professor of Electrical and Computer Engineering at Old Dominion University. $\mathrm{He}$ is currently the Chief Departmental Advisor in Electrical and Computer Engineering. His current research interests are in the dielectrics and insulants. His primary research interests are in the areas of electron attachment in fluorine compounds, breakdown studies in compressed gases and vacuum, material characterization and simulation studies in compound semiconductors, and high power semiconductor switches. He is also working on projects for technology-enhanced education.

\section{STEPHEN A. ZAHORIAN}

Stephen Zahorian is Professor of Electrical and Computer Engineering at Old Dominion University and chairman of the department. His primary research interests are in the areas of automatic speech recognition and development of speech training aids for the hearing impaired. He is also working on projects for technology-enhanced education.

\section{OSCAR R. GONZALEZ}

Oscar González is an Associate Professor of Electrical and Computer Engineering at Old Dominion University. His research interests include education methods, multivariable system and control theory, robust control system design, nonlinear control systems, and artificial intelligence applications in the control of systems. He is also working on projects for technology-enhanced education.

\section{AMIT KUMAR H.}

Amit Kumar H. is a graduate student in the Department of Electrical and Computer Engineering at Old Dominion University working for his Masters Degree in Computer Engineering. His research interests include high performance computer architecture and image processing applications. $\mathrm{He}$ is also working on projects for technology-enhanced education.

JAMES F. LEATHRUM, JR.

James Leathrum is an Assistant Professor of Electrical and Computer Engineering at Old Dominion University. His primary research interests are in the areas of modeling and simulation, distributed systems, and formal methods in computer system design. He is also working on projects for technology-enhanced education. 